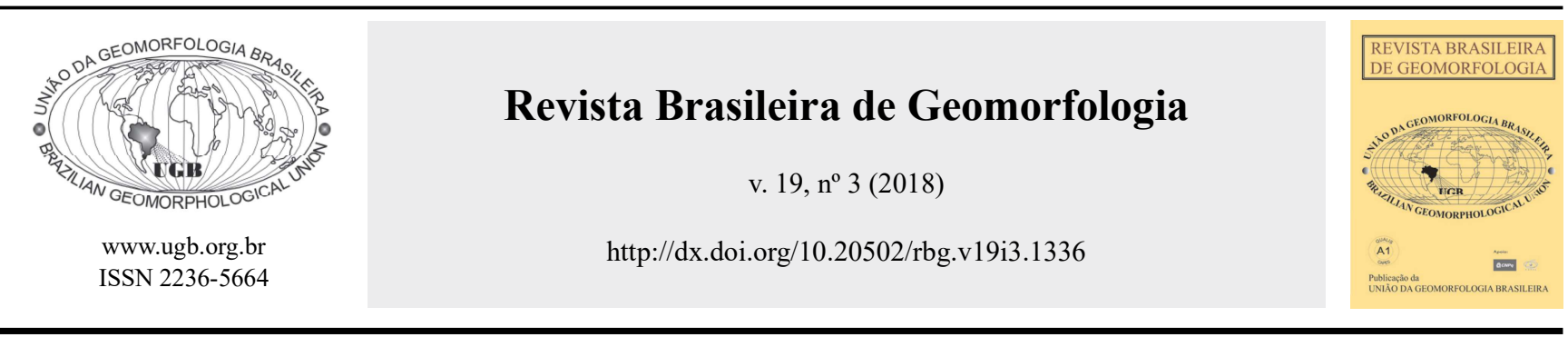

\title{
SUPERFÍCIES DE CIMEIRA DO PLANALTO DAS ARAUCARIAS - SUL DO BRASIL
}

\author{
SUMMIT SURFACES OF THE ARAUCARIAS PLATEAU - \\ SOUTH OF BRAZIL
}

\author{
Vitor Hugo Rosa Biffi \\ Departamento de Geografia, Universidade Estadual do Oeste do Paraná \\ Rua Maringá 1.200, Francisco Beltrão, Paraná. CEP 85.605-010. Brasil \\ E-mail:vhugorosabiffigmail.com
}

Julio Cesar Paisani

Departamento de Geografia, Universidade Estadual do Oeste do Paraná Rua Maringá 1.200, Francisco Beltrão, Paraná. CEP 85.605-010. Brasil

E-mail: juliopaisani@hotmail.com

\begin{tabular}{l} 
Informações sobre o Artigo \\
\hline Data de Recebimento: \\
21/11/2017 \\
Data de Aprovação: \\
09/05/2018
\end{tabular}

Palavras-chave:

Superfícies Aplainadas;

Superfície de Erosão;

Litoestrutura; Etchplanação.

\section{Keywords:}

Planation Surfaces; Erosion

Surface; Lithostruture;

Etchplanation.

\section{Resumo:}

No Sul do Brasil foram reconhecidas superficies de cimeira que balizaram estudos de evolução do relevo na porção oriental dessa região, sobre terrenos cristalinos/cristalofilianos e borda da Bacia do Paraná. No que se refere a esta última, uma unidade geomórfica dominante no sul do Brasil, o Planalto das Araucárias, ainda carece de individualização e caracterização de superfícies de cimeira em mesoescala, tão pouco da compreensão do papel da litoestrutura no estabelecimento das possíveis superfícies dessa categoria. Diante disso, o presente artigo traz resultados da caracterização das superfícies de cimeira do Planalto das Araucárias. A identificação e caracterização das superfícies de cimeira do Planalto das Araucárias foram realizadas a partir de levantamento e elaboração de produtos cartográficos, que consistiu em quatro etapas: 1) elaboração de modelos digitais de terreno (Índice de Rugosidade do Terreno- IRT, relevo sombreado e hipsométrico) e perfis topográficos; 2) cotejamento desses primeiros com mapas geológicos e geomorfológicos; 3 ) interpretação e análise dos diferentes produtos gerados; e 4) aferição dos resultados com observações em campo. O produto gerado com o IRT, em conjunto com a imagem sombreada, permitiu distinguir três superfícies de cimeira no Planalto das Araucárias, aqui referidas como superfícies de Vacaria, Palmas/Caçador e Superfície de Pinhão/Guarapuava, entre 760 a $+1300 \mathrm{~m}$ de altitude, as quais se encontram na borda leste desse planalto. O IRT revelou que tais superfícies apresentam aspecto plano, embora dissecada, e com quatro a quatorze níveis altimétricos internos (embutidos). A espacialização das superfícies, a extração de perfis topográficos e o respectivo cotejamento com 
mapas geológicos e geomorfológicos permitiram avaliar o controle litoestrutural e a ocorrência de níveis geomórficos individualizados previamente na literatura. Verificou-se que as superfícies transpõem limites laterais dos derrames básicos, intermediários e ácidos, embora predominem sobre estes últimos. Isso leva a pensar que as superfícies de cimeira estão longe de serem consideradas como superfícies controladas apenas pela litologia, como aventada na literatura de forma generalizada para todo o território nacional. Igualmente, limites laterais das superfícies e níveis altimétricos internos das superfícies coincidem, em partes, com falhas/fraturas, apontando para controle neotectônico. A cobertura superficial caracterizada em trabalhos da literatura, aqui revisados, apontam para ação de etchplanação na evolução das superfícies de cimeira, sobretudo entre o Plioceno a Pleistoceno Médio, com remoção de coberturas preexistentes diante de variações climáticas no Quaternário Tardio.

\begin{abstract}
:
In the South of Brazil, it was recognized summit surfaces that marked studies of the evolution of the relief in the eastern portion of this region, on crystalline / crystallophile rocks and border of the Paraná Basin. Regarding the latter, a dominant geomorphic unit in the south of Brazil, the Araucaria Plateau, still lacks the individualization and characterization of mesoscale summit surfaces, as well as the understanding of the role of lithostructure in the establishment of these possible surfaces of this category. Therefore, the present article presents results of the characterization of the summit surfaces of the Araucaria Plateau. The identification and characterization of the summit surfaces of the Araucaria Plateau were carried out from the survey and elaboration of cartographic products, which consisted of four stages: 1) elaboration of digital terrain models (TRI - Terrain Roughness Index, shaded relief and hypsometric) and topographic profiles; 2) comparing these with geological and geomorphological maps; 3 ) interpretation and analysis of the different products generated; and 4) measurement of results with field observations. The identification and characterization of the surfaces of the Araucaria Planalto summit were carried out from the survey and elaboration of cartographic products, which consisted of four stages: 1) elaboration of digital terrain models (IRT Terrain Roughness Index, shaded relief and hypsometric) and topographic profiles; 2) comparing these with geological and geomorphological maps; 3) interpretation and analysis of the different products generated; and 4) measurement of results with field observations. The product generated with the IRT, together with the shaded image, allowed to distinguish three summit surfaces in the Araucaria Plateau, here referred to as Vacaria, Palmas / Caçador and Pinhão / Guarapuava surfaces, between 760 and +1300 m a.s.l, which are on the eastern edge of this plateau. IRT revealed that these surfaces have a flat, albeit dissected, aspect and four to thirteen internal altimetry levels (inlays). Surface spatialization, the extraction of topographic profiles and their comparison with geological and geomorphological maps made it possible to evaluate the lithostructural control and the occurrence of individualized geomorphic levels previously in the literature. It has been found that the surfaces transpose lateral limits of the basic, intermediate and acid spills, although they predominate over the latter ones. This leads us to think that the summit surfaces are far from being considered as surfaces controlled only by lithology, as has been widely reported in the literature for the entire national territory. Likewise, lateral boundaries of the surfaces and altimetric internal levels of the surfaces coincide, in parts, with faults / fractures, pointing to neotectonic control. The surface cover characterized in the literature review, here reviewed, point to etchplanation in the evolution of the summit surfaces, especially between the Pliocene to the Middle Pleistocene, with removal of preexisting coverings in the face of climatic variations in the Late Quaternary.
\end{abstract}

\section{Introdução}

A identificação de superfícies aplainadas é um problema clássico da ciência geomorfológica (ADAMS,1975). Modelos conceituais a respeito de sua gênese e evolução têm sido propostos ao longo da consolidação da geomorfologia enquanto campo científico (VITTE, 2011; SALGADO, 2007), todos utilizando terminologias próprias para se referir a superfícies aplainadas, tais como: peneplanos, pediplanos, etchplanos, superfícies estruturais (DAVIS,1899; WAYLAND, 1975; KING, 1953; AB'SÁBER 1960a; BIGARELLA et al., 1965), ou simplesmente superfícies aplainadas (CÔRREA e MENDES, 2002; PAISANI et al., 2008). Independente 
da validade dessas terminologias, e respectivos modelos conceituais, são reconhecidas superfícies aplainadas ao longo das áreas emersas do globo (ADAMS,1975; RABASSA et al., 2010, RABASSA e OLLIER, 2014).

A identificação de superfícies aplainadas no Brasil teve seu auge nas décadas de 1950 e 1960 (DE MARTONE, 1943; KING, 1956; AB'SABER, 1962; BIGARELLA et al., 1965; ANDRADE, 1958; MABESSOONE, 1966; ANDRADE e LINS, 1965) cujos trabalhos destacam a gênese e evolução dessas superfícies vinculadas a ciclos de erosão, que podem ter ocorrido do Cretáceo até o Pleistoceno Inferior. A forma plana das superfícies decorreria de atuação de fenômenos vinculados a climas propícios a erosão mecânica "agressivos" (AB'SÁBER, 1965), e em alguns casos a neotectônica (DE MARTONE, 1943; FREITAS, 1951; MARQUES NETO e PEREZ FILHO, 2013).

No plano nacional, em escalas regionais, cerca de quatro a sete níveis altimétricos foram identificados como remanescentes de superfícies aplainadas (DE MARTONE, 1943; KING, 1956; BARBOSA, 1959; AB'SABER, 1962; BIGARELLA et al., 1965; VALADÃO, 1998). Procurando estabelecer as diferentes superfícies reconhecidas ao longo do território brasileiro quanto a posição topográfica, de modo a permitir sua correlação, Ab'Saber (1960a) sugere como critério descritivo designá-las de: A) superficies de cumiada ou superficies de cimeira, B) superficies intermontanas, C) superficies fósseis em exumação e D) superfícies de eversão. Dentre elas, se destaca as superfícies de cimeira, posicionadas na atualidade em níveis elevados, geralmente acima de $1.000 \mathrm{~m}$, pois seriam as superfícies mais antigas e relíctos de prolongadas fases de erosão mecânica.

A partir de critérios genéticos, Ab'Sáber (1960b) define superfície de cimeira como superfície aplainada gerada a partir de processos de dobramentos relacionados aos ressaltos de epirogêneses pós-cretácea. Via de regra, estão inscritas nas abóbadas de arqueamento ou nos altos das dorsais dos núcleos de escudos, aparecendo largamente em diversos quadrantes do Escudo Brasileiro, assim como, no Escudo Uruguaio-Sul Rio Grandense.

No Sul do Brasil foram reconhecidas superficies de cimeira que balizaram estudos de evolução do relevo em escala regional, tais como: Superfície de Caçapava do Sul, Purunã e Reverso da Serra do Mar (AB'SÁBER 1960a; ANDRADE et al., 1963; AB'SÁBBER e BIGARELLA, 1961; BIGARELLA et al., 1965), correlativas a ciclo de pediplanação pós-cretácea. Estas superfícies foram individualizadas e caracterizadas na porção oriental dessa região, sobre terrenos cristalinos/ cristalofilianos e borda da Bacia do Paraná. No que se refere a esta última, uma unidade geomórfica dominante no sul do Brasil, o Planalto das Araucárias, ainda carece de individualização e caracterização de superfícies de cimeira em mesoescala, tão pouco da compreensão do papel da litoestrutura no estabelecimento dessa categoria de superfície. Diante disso, o presente artigo traz resultados da caracterização das superfícies de cimeira do Planalto das Araucárias e discute controles litoestruturais na individualização dessas superfícies na paisagem.

\section{2. Área de estudo}

Planalto das Araucárias é uma unidade geomorfológica que ocupa cerca de $3 / 4$ do território da região sul do Brasil (PAISANI et al., 2014) (Fig. 1). Ele exibe diferentes níveis altimétricos (600 a $1.800 \mathrm{~m}$ de altitude) na sua maioria suavemente ondulados, que localmente foram reconhecidos como remanescentes de superfícies aplainadas (PAISANI et al., 2008; 2013). Essas superfícies são mantidas por derrames vulcânicos de natureza básica (predominante), intermediária e ácida do Neocretáceo da Bacia do Paraná (FODOR et al., 1989; NARDY et al., 2002; SCHENATO et al., 2003; LICHT, 2018). A maior extensão desse planalto se encontra em zona climática subtropical úmida, com precipitação média entre 1.250 a $2.000 \mathrm{~mm} . \mathrm{ano}^{-1} \mathrm{e}$ temperatura média anual entre 14 e $22^{\circ} \mathrm{C}$ (NIMER, 1990). A associação entre substrato vulcânico básico e clima subtropical úmido é a principal responsável pelo desenvolvimento de perfis de intemperismo químico com Latossolos de diferentes espessuras (PAISANI et al., 2008; 2013; BHERING e SANTOS, 2008). Esses solos são poligenéticos e suas diferentes espessuras decorrem da renovação por processos de etchplanação ao longo do Quaternário (PAISANI et al., 2013). Os remanescestes de superfícies aplainadas situadas acima $1.200 \mathrm{~m}$ de altitude são mantidos por derrames ácidos e apresentam Neossolos Litólicos com horizonte A preto moderno $(<830$ anos AP). Nesses locais também são registrados sedimentos colúviais, colúvio-alúviais, aluviais e paleossolos (PAISANI et al., 2014; PEREIRA, 2017). 


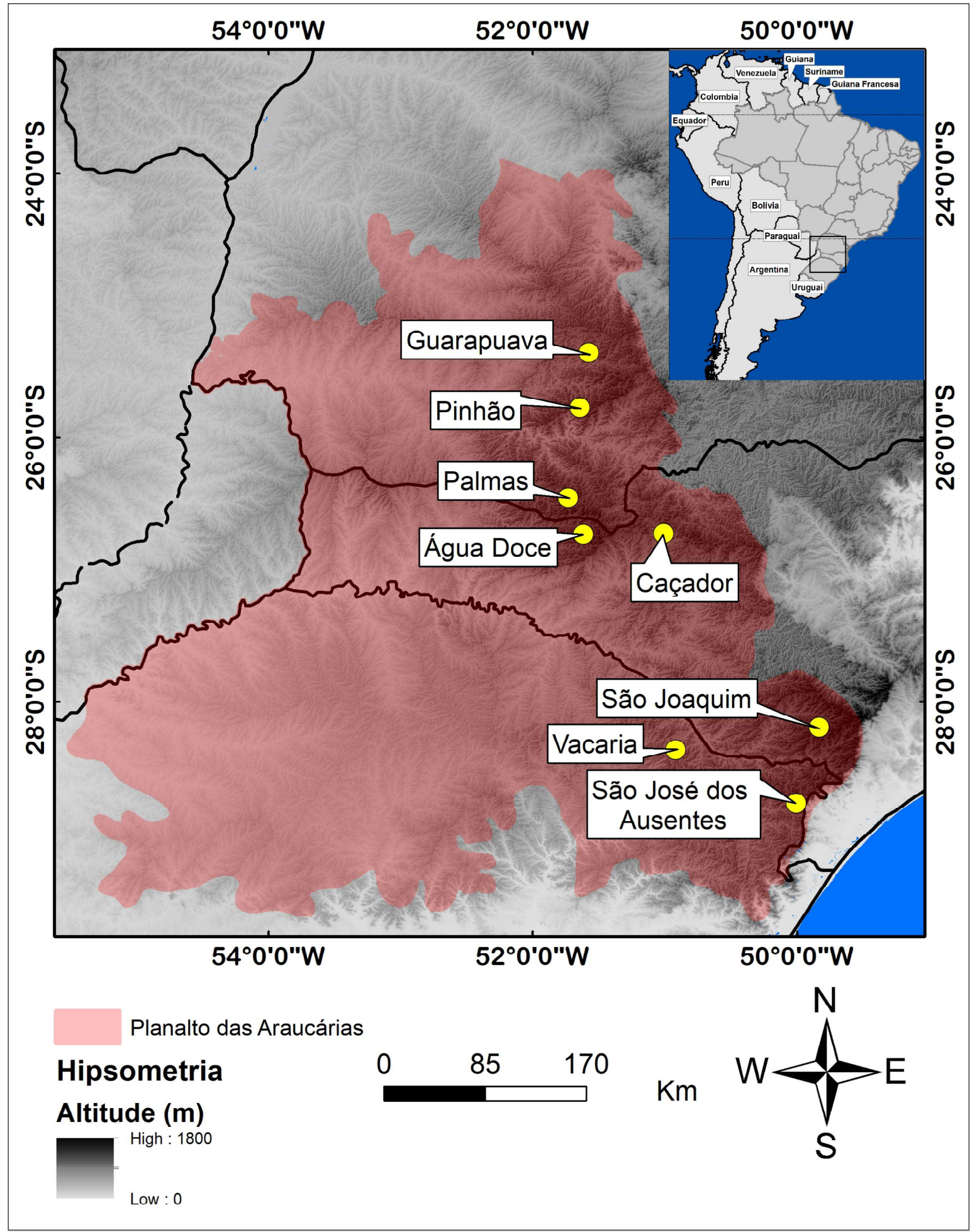

Figura 1 - Planalto das Araucárias no Sul do Brasil, cujos setores mais elevados se situam na sua porção leste e coincidem com os limites dos derrames vulcânicos (Formação Serra Geral) em relação as demais unidades morfográficas. Nesses locais se encontram os municípios de São José dos Ausentes, Vacaria, São Joaquim, Caçador, Água Doce, Palmas, Pinhão e Guarapuava”.

\section{Materiais e Métodos}

Para a espacialização de unidades de relevo, diversos critérios vêm sendo utilizados apoiados em técnicas de geoprocessamento e sistemas de informação geográfica (FLORENZANO, 2008), baseados em dados morfométricos do terreno, entre 
eles se destacam o índice de posição topográfica (JENNESS, 2006; DE RÉU 2011, 2013), a Diferença Mediana Absoluta (MAD) (TREVISANI, 2015) e o Índice de Concentração da Rugosidade (SAMPAIO E AUGUSTIN, 2014). Para o caso de estudos regionais, se sobressai o Índice de Rugosidade do Terreno (IRT) (RILEY et al., 1999), o qual é utilizado para verificar a rugosidade do terreno diante da variação altimétrica ao redor de um determinado ponto da superfície. Nessa abordagem, quanto mais uniforme for o relevo, quanto a sua altimetria, em uma determinada área, menor será o índice de rugosidade. Diante disso, o IRT se mostra com potencial para a individualização de superfícies entendidas como aplainadas.

A identificação e caracterização das superfícies de cimeira do Planalto das Araucárias foram realizadas a partir de levantamento e elaboração de produtos cartográficos, que consistiu em quatro etapas: 1) elaboração de modelos digitais de terreno (IRT, relevo sombreado e hipsométrico) e perfis topográficos; 2) cotejamento desses primeiros com mapas geológicos e geomorfológicos; 3) interpretação e análise dos diferentes produtos gerados; e 4) aferição dos resultados com observações em campo.

Os modelos digitais de terreno derivaram de bases de dados de imagens Shuttle Radar Topography Mission (SRTM), com resolução de 30 e 90 m, que geraram diferentes produtos. As imagens SRTM foram adquiridas junto ao site do USGS (https://earthexplorer. usgs.gov/), seguida pela conversão para o sistema de referência de coordenadas planas (UTM), fuso 22s, e agrupadas para constituir mosaico das cenas referente ao Planalto das Araucárias.

O IRT foi obtido no mosaico das imagens do SRTM com resolução de $90 \mathrm{~m}$, enquanto que o relevo sombreado e o hipsométrico derivaram do mosaico das imagens com resolução de $30 \mathrm{~m}$. No caso do relevo sombreado utilizou-se azimute de $315^{\circ}$ e altitude de $45^{\circ}$, como recomenda Freitas et al. (2006). As delimitações das superfícies de cimeira foram determinadas a partir do critério de zonas homologas, descritos por Moreira (2003). Para todos os procedimentos supracitados foi utilizado as ferramentas e recursos do software Qgis 2.8 .

Os mapas geológicos foram adquiridos junto ao site do CPRM (http://geosgb.cprm.gov.br/), folhas
SG22 e SH22 em escala 1: 1.000.000. Também foram adquiridos mapas geológicos com limites estaduais de Santa Catarina (1:500.0000), Paraná (1:250.000) e Rio Grande do Sul (1:700.000). Com relação aos mapas geomorfológicos, foram obtidas as cartas do Projeto Radam Brasil, disponibilizados pelo IBGE (ftp:// geoftp.ibge.gov.br), folhas SG22 e SH22, em escala 1:250.000. Igualmente aos modelos digitais do terreno, software Qgis 2.8 serviu de plataforma na obtenção dos cotejamentos de resultados.

\section{Resultados e Discussão}

\section{1 Índice de Rugosidade do Terreno}

O produto gerado com o IRT, em conjunto com a imagem sombreada, permitiu distinguir três superfícies de cimeira no Planalto das Araucárias (Figura 2). Esses compartimentos estão dentro da classe level de Riley et al. (1999) e apresentaram homogeneidade quanto ao índice e, via de regra, estão inseridas na borda leste do Planalto das Araucárias, que coincide com os maiores valores altimétricos desse planalto (Figura 1,2). Os compartimentos foram designados pela conjugação do nome dos municípios de maior expressão areal e a respectiva superfície de cimeira em que eles ocorrem, e com base na literatura, de modo que os três compartimentos se referem as superfícies de Vacaria (AB'SÁBER,1969), Palmas/Caçador (PAISANI et al., 2008; SORDI et al., 2016) e Superfície de Pinhão/Inácio Martins/Guarapuava (PAISANI et al., 2008).

A frequência absoluta dos valores IRT, obtidos pelo histograma das unidades mapeadas, possibilitou analisar o grau de nivelamento (level) das superfícies de cimeira. No geral, os valores mais frequentes ficaram entre 4 e 18, indicando que as unidades geomórficas mapeadas apresentam aspecto de superfície plana (Figura 3). Por outro lado, ao observar as superfícies na paisagem (Figura 4), perceberam-se sutis diferenças em seus graus de dissecação, dando aspecto as superfícies de morfologias suavemente onduladas. Tal fato é coerente com os perfis topográficos extraídos automaticamente, demonstrados nos próximos itens. No geral, comparando os histogramas percebe-se que para as superfícies de cimeira de Pinhão/Guarapuava e de Palmas/Caçador (Figura 3 B, C), a distribuição do índice mostra heterogeneidade, expressando maior dissecação nelas que na Superfície de Vacaria. 


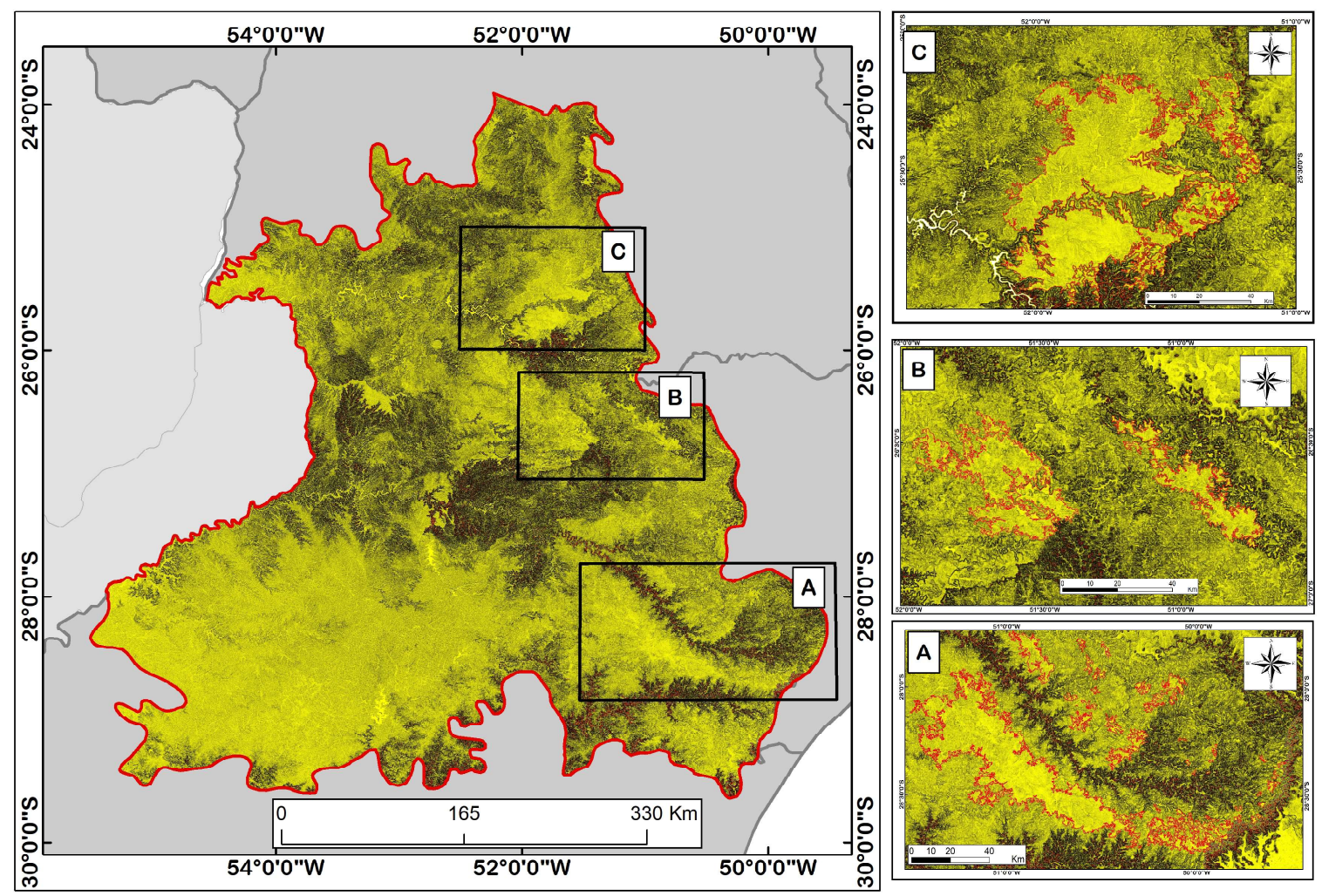

Figura 2 - Individualização das superficies de Vacaria (A), Palmas/Caçador (B) e Superficie de Pinhão/Guarapuava (C) no Planalto das Araucárias, por meio do Índice de Rugosidade do Terreno.

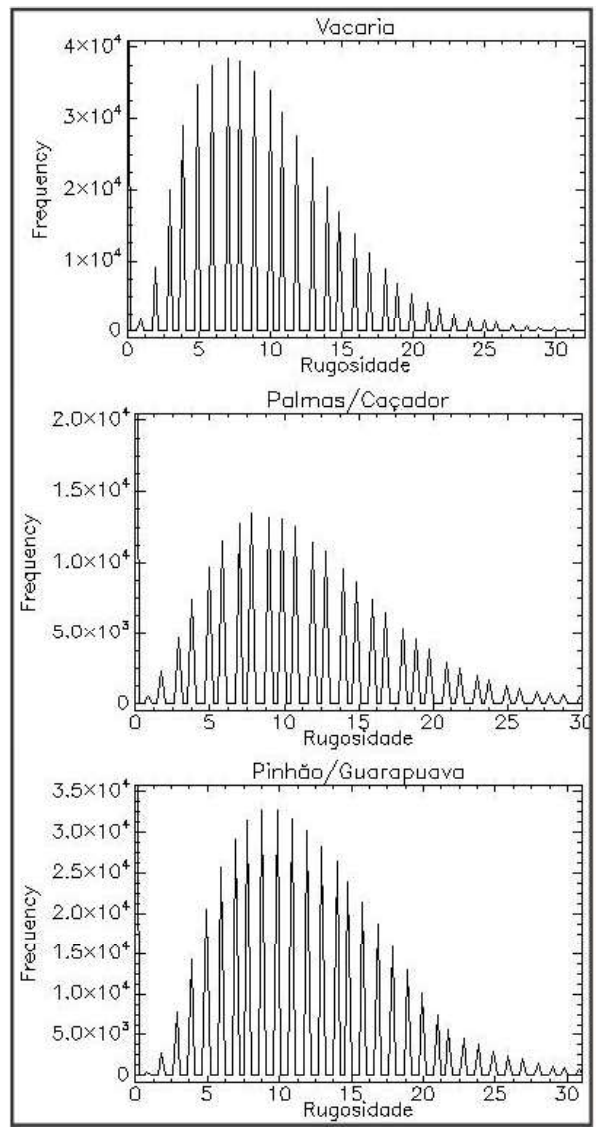

Figura 3 - Histogramas de frequência absoluta dos valores IRT para as superficies de cimeira individualizadas. 


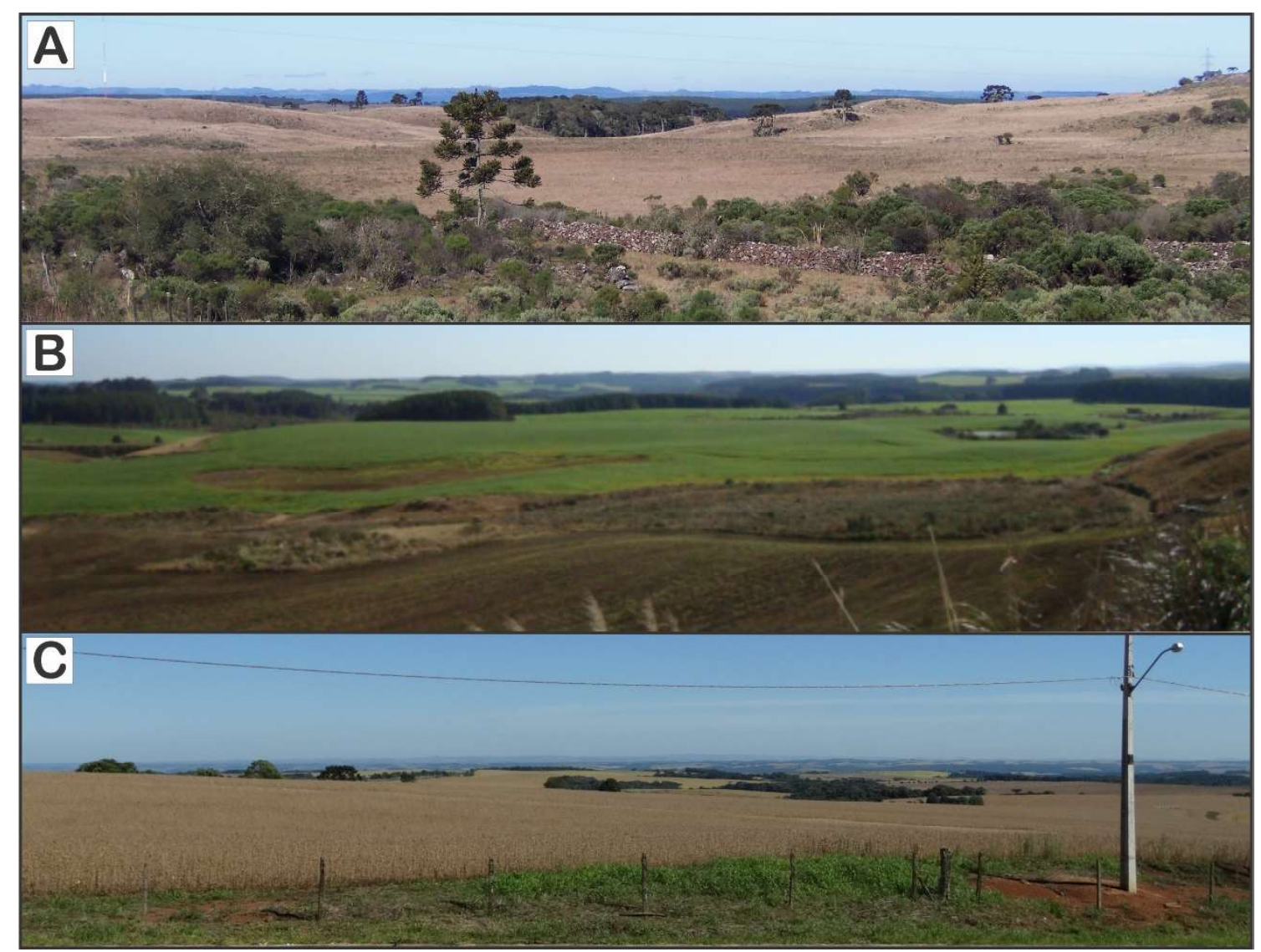

Figura 4 - Paisagens das Superficies de Vacaria (A), Palmas/ Caçador (B) e Superficie de Pinhão/Guarapuava (C).

\subsection{Superfície de Vacaria}

A Superfície de Vacaria ocorre nos municípios de Bom Jesus, Vacaria, Muitos Capões, Capão Bonito do Sul, Esmeralda e São José dos Ausentes no estado do Rio Grande do Sul, com altitudes que variam de 800 a $\sim 1.250 \mathrm{~m}$ de altitude. Em Santa Catarina, a superfície se estende pelos municípios de Bom Jardim da Serra, São Joaquim, Painel, Lages, Capão Alto, Campo Grande do Sul, Cerro Negro e Anita Garibaldi, embora de forma descontínua configurando relevos residuais (Figura 5A). No estado do Rio Grande do Sul, a superfície apresentou disposição alongada no sentido ESE-WSW, exibindo nítido aumento das cotas altimétricas para ESE, próximo à escarpa da Serra Geral, enquanto que a distribuição espacial dos relevos residuais coincide com áreas de maior dissecação do rio Pelotas e seus afluentes.

Essa área corresponde a "superfície aplainada desnudada" reconhecida por Justus et al. (1986), ou simplesmente Superfície de Vacaria proposta por Ab'Sábber (1969). Este último autor não faz referência a distribuição espacial dessa superfície, apenas menciona que ela encontra entre 950 a $1.100 \mathrm{~m}$ de altitude, perdendo altimetria para oeste, sudoeste e sul de forma suave até entre 750 e $800 \mathrm{~m}$, o que está em acordo com os resultados aqui apresentados. O perfil topográfico obtido cruzando superfície no sentindo $\mathrm{N}-\mathrm{S}$ demonstra que a superfície apresenta aspecto de abóboda, fato que está em acordo com Ab'Sáber (1969), quando o mesmo sugere que após o seu aplainamento, a superfície foi deformada em arqueamento durante fases de soerguimento epirogenético nos períodos Cretáceo e Terciário (Paleógeno) (Figura 5B).

Com relação a estrutura litológica, a Superfície de Vacaria é mantida por derrames vulcânicos básicos e ácidos. Os derrames básicos integram a sequência inferior e se dividem em fácies Esmeralda e Gramado, enquanto que derrame ácido se encontra na sequencia intermediária e corresponde a fácies Caxias (PEATE, 1989; PEATE et al., 1992; FREITAS et al. 2002). Esse resultado sugere não se tratar de superfície controlada especificamente por derrames ácidos, como aventava Ross (1991), mas sim superfície com níveis topográficos controlados por diferenças litológicas entre derrames básicos e ácidos, bem como estruturas como falhas/fraturas. 


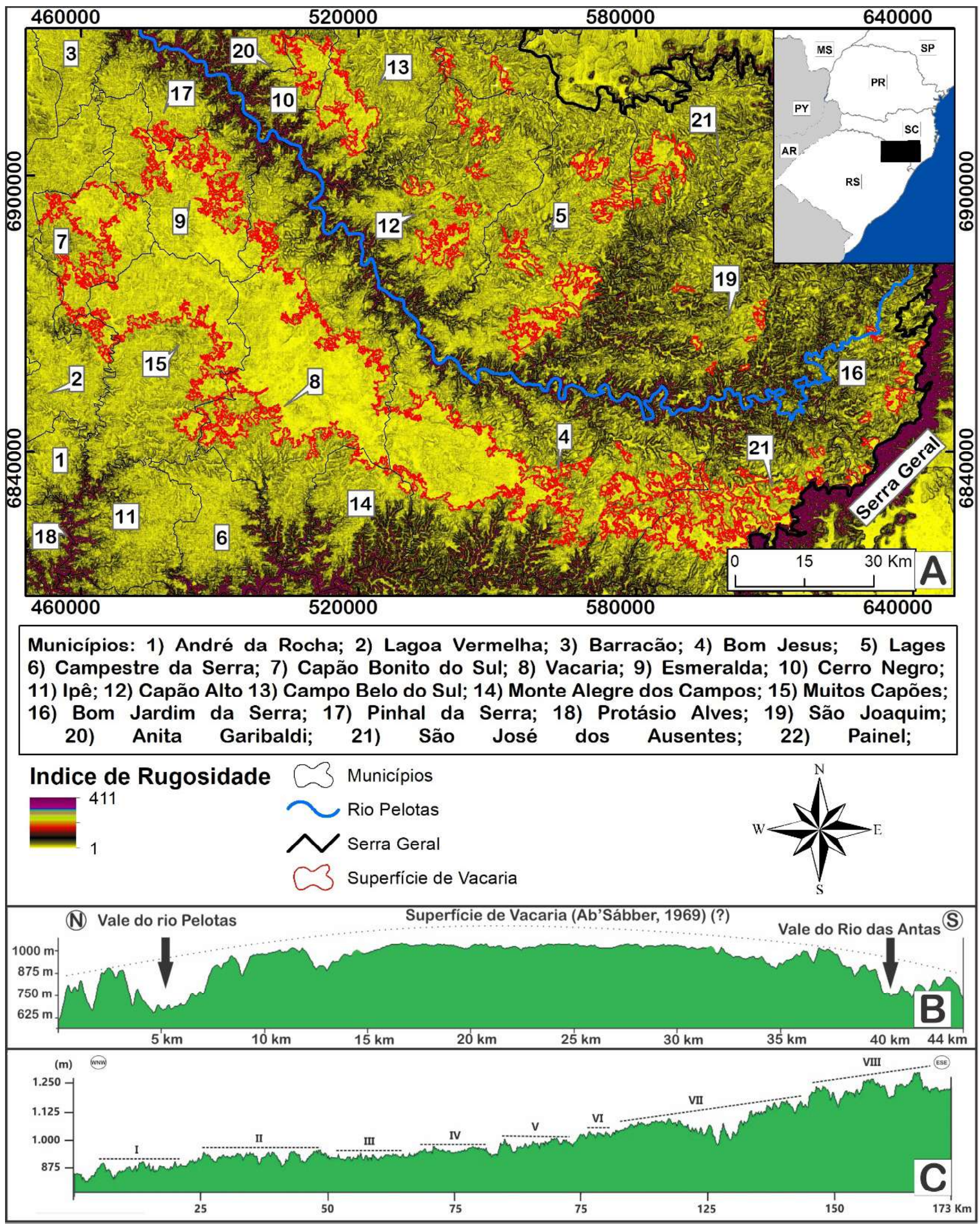

Figura 5- Individualização da Superficie de Vacaria, por meio do Índice de Rugosidade do Terreno e imagem sombreada (A). Perfil topográfico da Superficie de Vacaria no sentido N-S (B). Niveis topográficos identificados na Superficie de Vacaria (C). 
Enquanto detalhamento da topografia interna da Superfície de Vacaria, aplicou-se a técnica de nivelamento a perfil topográfico obtido de NW para SE, cruzando longitudinalmente a superficie, e foi identificado oito níveis topográficos (Figura 5C), dos quais quatro (níveis I, II, III e IV) estão escalonados com aspecto de "teclas de piano", dois como superfícies típicas escalonadas (V e VI) e dois níveis inclinados e escalonados para NW (VII e VIII). Tais níveis topográficos coincidem com limite de fácies de derrames (II/III e VI/VII) e falhas/fraturas (demais níveis) de mapeamento geológico realizado pela WILDNER et al. (2014). A influência de processos morfotectônicos entre o Paleógeno e o Neógeno nas bacias dos rios Lava-Tudo e Pelotas foram sugeridas por Santos (2017), controlando a rede de drenagem e a evolução do relevo.

Por outro lado, Oliveira (1995) reconheceu os dois níveis topográficos identificados por Justus et al. (1986) e atribuiu correlação altimétrica, respectivamente, as Superfícies Sul-Americana e Velhas de King (1956). Entretanto, a autora descreve formações superficiais caracterizadas por significativa descontinuidade entre "coberturas móveis" (Latossolos) e alteritas. Essa discordância, por vezes de ordem erosiva, foi um dos atributos para Oliveira (1995) sugerir que a Superfície de Vacaria teria passado, ao longo do Terciário, pela ação da etchplanação.

De fato, trabalho recente sobre as formações superficiais encontradas ao longo do ápice da Superfície de Vacaria (cotas acima de $1.100 \mathrm{~m}$ de altitude) aponta para delgada cobertura coluvial dispostas em rampas, hollows de cabeceiras de drenagem e colmatando fundos de vales de baixa ordem hierárquica $\left(<4^{\mathrm{a}}\right.$ ordem - PAISANI et al., 2014, PEREIRA et al., 2016). Esses colúvios, em especial aqueles que colmataram os fundos de vale, foram gerados pelo escoamento superficial durante o Quaternário Tardio, como sugerem idades por luminescência óticamente estimulada (PEREIRA, 2017). Esses achados mostram que a designação de "superfície aplainada desnudada", ou seja, superfície com remoção de coberturas preexistentes, está vinculada a dinâmica evolutiva de colinas e fundos de vales durante o Quaternário Superior (PEREIRA, 2017), e não necessariamente a paleosuperfícies.

\subsection{Superfície de Palmas/Caçador}

Para o caso da região Sudoeste do estado do Paraná e Meio Oeste do estado catarinense, a aplicação do IRT permitiu individualizar e mapear dois setores: Palmas e Caçador. O primeiro setor ocorre nos municípios de Palmas (PR), Água Doce (SC), General Carneiro (PR), Passos Maia (SC) e Macieira (SC), constituindo aproximadamente 949,59 $\mathrm{km}^{2}$ de área total. Trata-se de uma superfície alongada no sentido NW-SE com aproximadamente 62 $\mathrm{km}$ de extensão, e altitudes que variam de 1.021 a $1.374 \mathrm{~m}$. Já o segundo setor se encontra a $32 \mathrm{Km}$ do primeiro, tem altitudes que variam de 989 a $1.308 \mathrm{~m}$ de altitude. Ela se estende pelos municípios de Caçador (SC), Matos Costa (SC), Calmon (SC), e Lebon Régis (SC) com disposição espacial alongada, porém corresponde a $1 / 3$ da área da primeira $\left(318,25 \mathrm{Km}^{2}\right)$, e se mostra descontínua lateralmentente, assumindo a forma de relevos residuais, dispostos no sentido NW-SE (Figura 6).

A disposição espacial das superfícies alinhadas em sentido NW-SE em cotas altimétricos semelhantes sugerem que elas integram uma única superfície, que se configura em dois compartimentos isolados por uma zona mais dissecada pela drenagem dos sistemas hidrográficos dos Rio Iguaçu e Uruguai. De fato, a literatura indica a existência do Planalto de Caçador como correlato ao Planalto de Palmas/Água Doce (SORDI et al. 2016). Portanto, acredita-se que são dois setores de uma única superfície, e por isso foi intitulado de superficie de Palmas/Caçador.

Com relação aos aspectos litológicos, as superfícies mapeadas são mantidas em sua maioria por rochas da Fácies Clevelândia na região de Palmas, e rochas da Fácies Anita Garibaldi na região de Caçador (NARDY et al. 2011). Tratam-se de rochas vulcânicas ácidas (Unidade Palmas), e corresponde a sequência intermediária dos derrames vulcânicos da província magmática do Paraná (PEATE et al. 1988; 1992). Apesar das limitações apresentadas pela escala dos mapeamentos, foi possível verificar em campo que a superfície transpõe os limites laterais dos derrames.

Aplicando a técnica de nivelamento a perfil topográfico obtido de $\mathrm{W}$ para $\mathrm{E}$ englobando ambos os setores percebe-se aspecto de bloco basculado em direção a W (Figura 6B), estando em conformidade com a direção do padrão de basculamento de blocos nas bordas da Bacia do Paraná (SAADI 1993; SAADI et al., 2005). Cotejando os limites da superfície com falhas contidas em mapas geológicos (Figura 6B), verifica-se que os limites gerais da superfície se aproximam das principais falhas da referida bacia para a área (Zona de Falha de Caçador-NW e Zona de Falha de Lancinha / 
Cubatão-NE) (ZALAN et al., 1990; FREITAS et al., 2006). Tais fatos levam a pensar que $o$ aspecto basculado constatado no perfil topográfico geral da superfície de Palmas/Caçador pode ser de ordem tectônica.

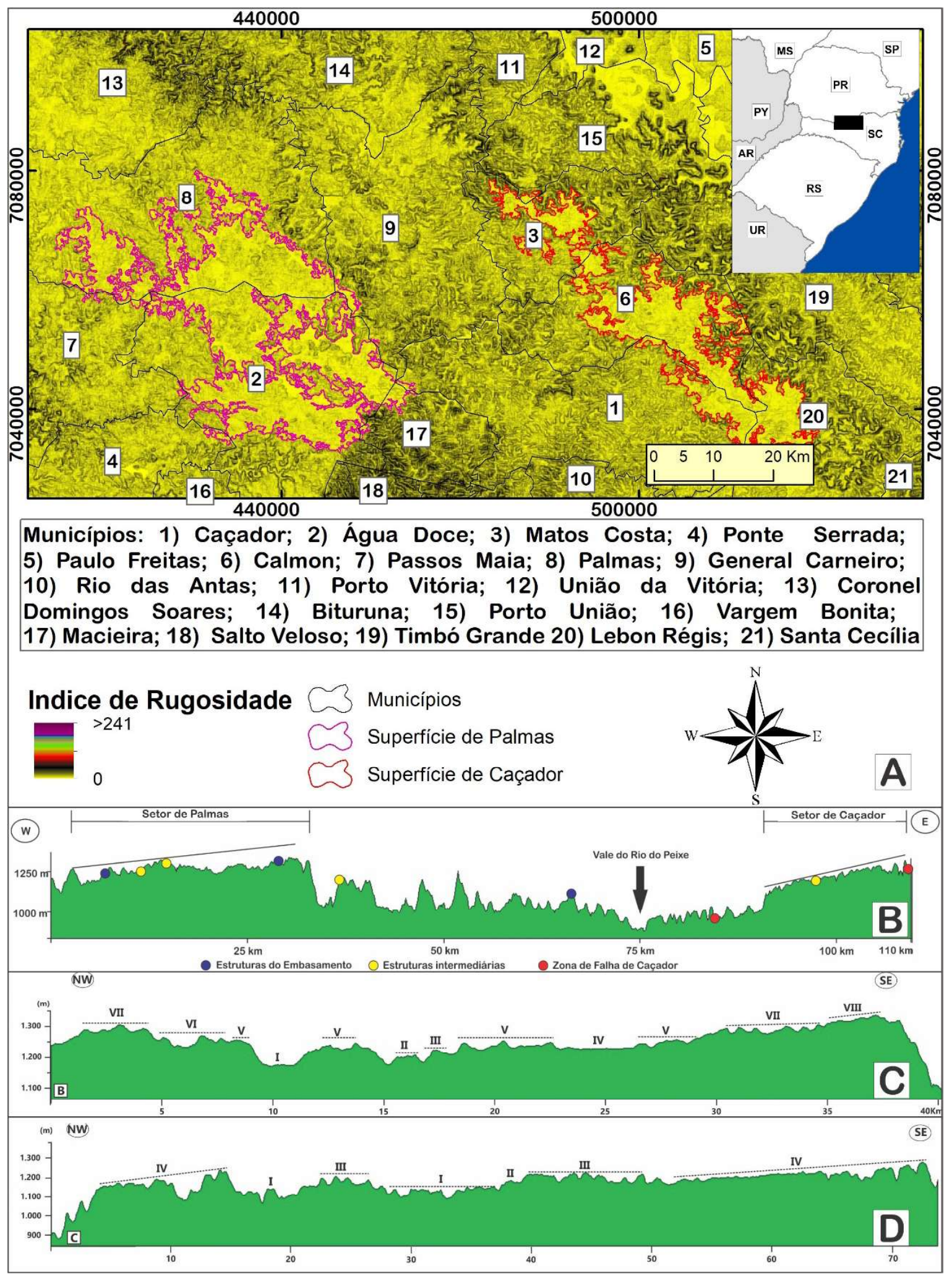

Figura 6 - Individualização da Superficie de Palmas/Caçador, por meio do Índice de Rugosidade do Terreno e imagem sombreada (A). Perfil topográfico no sentido W-E demonstrando a descontinuidade entre setor de Palmas e de Caçador (B). Niveis topográficos identificados nos setores de Palmas (C) e Caçador (D) 
Enquanto detalhamento da topografia interna o setor de Palmas, a técnica de nivelamento de perfil topográfico obtido em sentido SE-NW, permitiu identificar a presença de nove níveis altimétricos, aos quais podem refletir a interação entre contínuo aprofundamento do nível de base do rio Chapecó (nível de base local) e diferença litoestrutural dos litotipos dos derrames vulcânicos, formando relevos residuais (níveis II, III, V, VI e VII), ou ainda a movimentação de blocos por atividade tectônica, como o caso dos níveis VI e VIII que se encontram suavemente inclinado para NW (Figura 6C). Embora a escala dos mapeamentos geológicos generalize as estruturas tectônicas, há nítida coincidência entre o limite lateral dos níveis V/VII (distância lateral $28 \mathrm{Km}$ ) com falha/fratura registradas em referidos mapeamentos (Figura 6C).

No setor de Caçador a técnica de nivelamento aplicado a perfil topográfico obtido de NW para SE, cruzando longitudinalmente a superfície, permitiu identificar quatro níveis topográficos dispostos similarmente ao setor de Palmas (Figura 6 C,D), dos quais se destacam o nível III, enquanto relevos residuais, e o nível IV como superfícies suavemente inclinada para NW (Figura 6D).

Com relação às formações superficiais, estudos de Geomorfologia do Quaternário vêm sendo realizados no setor de Palmas à quase dez anos. A maioria dos registros foram encontrados em paleofundos de vales de baixa ordem $\left(<4^{\mathrm{a}}\right.$ ordem $)$ colmatados. Tais estudos revelaram informações importantes a respeito da geodinâmica superficial da área (PAISANI et al., 2012; 2013; 2014; 2016; GUERRA e PAISANI, 2013) apontando que o último evento de estabilidade da paisagem, com consequente desenvolvimento de perfis de solo, teria ocorrido até o final do Último Interestadial $(\geq 25.000$ anos cal. AP). Ao passo que no Último Máximo Glacial, mas sobretudo durante Holoceno, a morfogênese mecânica foi mais expressiva e desnudou encostas e colmatou fundos de vales de baixa ordem (PAISANI et al., 2014). A intensa morfogênese mecânica é vista como decorrente de mudanças hidrológicas associadas a variações climáticas durante o Quaternário Tardio.

\subsection{Superfície de Pinhão/Guarapuava}

A terceira superfície identificada, intitulada de Superfície de Pinhão/Guarapuava ocorre nos municípios de Guarapuava, Candói, Foz do Jordão, Inácio Martins, Pinhão e Reserva do Iguaçu (Figura 7A), com altitudes que variam de 768 a $1364 \mathrm{~m}$. A superfície apresenta forma de dois setores alongados, sentido NE-SW, dissecados pelo atual sistema hidrográfico do Rio Jordão (Figura 7A). O primeiro setor, a norte dos rios Jordão e Pinhão (setor Guarapuava), exibe aproximadamente $2111.8 \mathrm{~km}^{2}$ de área, enquanto o segundo, ao sul desse sistema hidrográfico (setor Pinhão), apresenta área aproximada de $1395 \mathrm{~km}^{2}$.

Trabalhos prévios na área que engloba superfície mapeada já identificaram superfícies de cimeira na região Centro-Sul paranaense, mas a sua espacialização diverge dos limites reconhecidos neste trabalho (IBGE, 1983; PAISANI et al. 2008; PEYERL, 2016). Para IBGE, (1983), a superfície corresponde a cimeira do Planalto dos Campos Gerais, e estaria sob a forma de dois remanescentes de superfície pediplanada, com aspecto retocado inumado/desnudada. Os autores não apontam a presença de depósitos correlativos a elaboração da superfície, dificultado a definição de superfície de erosão pediplanada.

Estudos posteriores de Paisani et al. (2008) reconheceu como superfície de cimeira (Pinhão/Inácio Martins/Guarapuava) a área entre $1.201 \mathrm{a} 1.300 \mathrm{~m}$ de altitude. Contudo, Peyerl (2016) reconheceu a presença como superfície de cimeira nas áreas acima de $950 \mathrm{~m}$ de altitude, além de outras superfícies mais baixas (Zona II - 950 a 730m e Zona I - abaixo de $730 \mathrm{~m}$ ). Para Paisani et al. (2008) esses níveis topográficos já expressariam superfícies interplanálticas e patamares extensos, enquanto que o IRT do presente trabalho mostra que os níveis identificados pelos autores estão contidos na superfície de cimeira de Pinhão/ Guarapuava.

A extração de perfil topográfico no sentido NWSE, longitudinalmente a disposição da superfície, revela que a mesma apresenta assimetria em relação a sua disposição topográfica (Figura 7B). O setor Guarapuava tem menor inclinação em direção ao vale do Rio Jordão, enquanto que o setor Pinhão apresenta maior inclinação e menor dissecação (Figura 7B). Resultados de parâmetros morfotectônicos na bacia do rio Jordão, sugerem reativações tectônicas no Cenozóico, decorrentes de movimentos na zona de Falha de Taxaquara (PEYERL, 2016). 


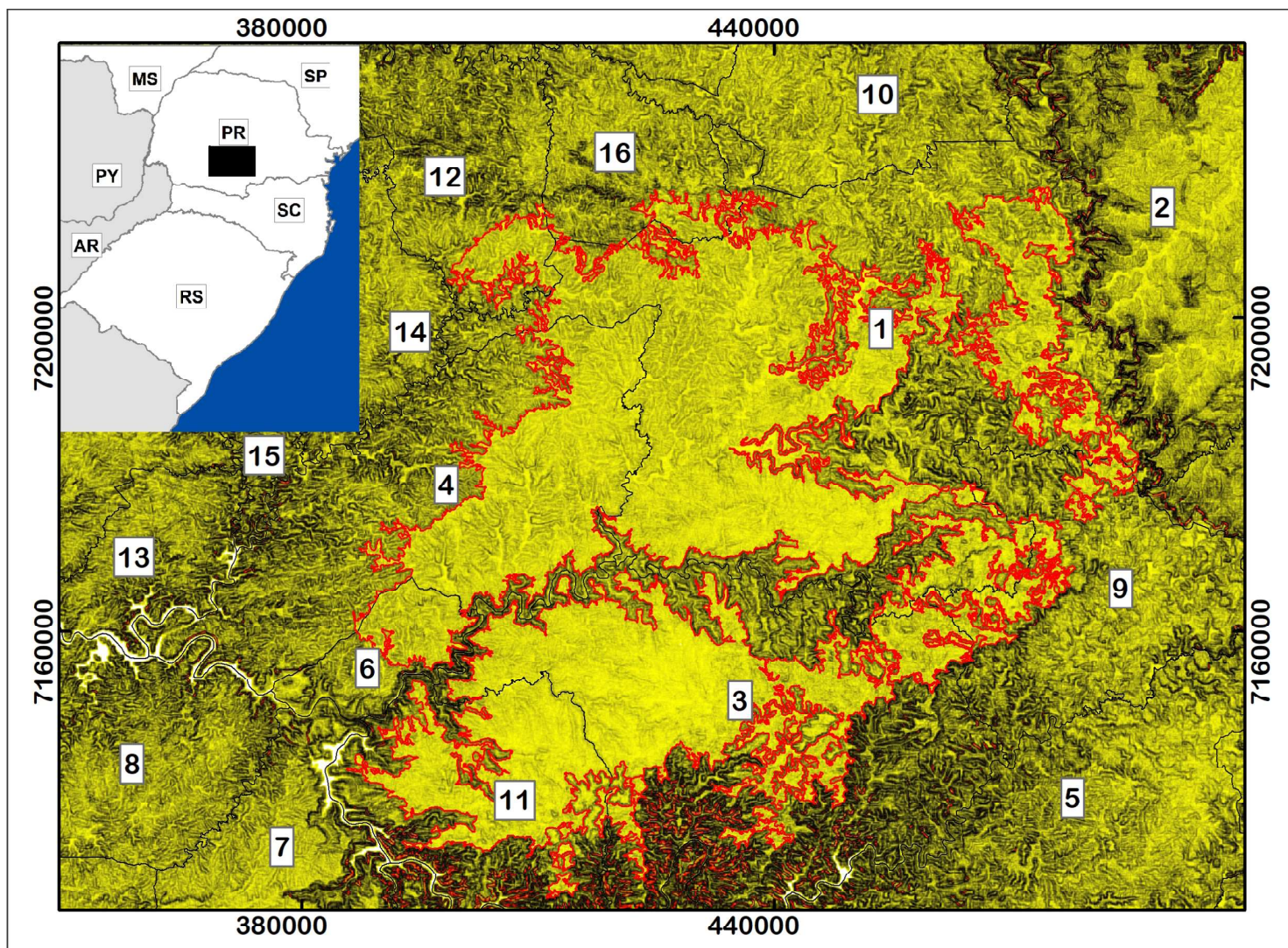

Municípios: 1) Guarapuava; 2) Prudentópolis; 3) Pinhão; 4) Candói; 5) Cruz Machado; 6) Foz do Jordão; 7) Mangueirinha; 8) Chopinzinho; 9) Inácio Martins; 10) Turvo; 11) Reserva do Iguaçu; 12) Goioxim; 13) Porto Barreiro; 14) Cantagalo; 15) Virmond; 16) Campina do Simão.
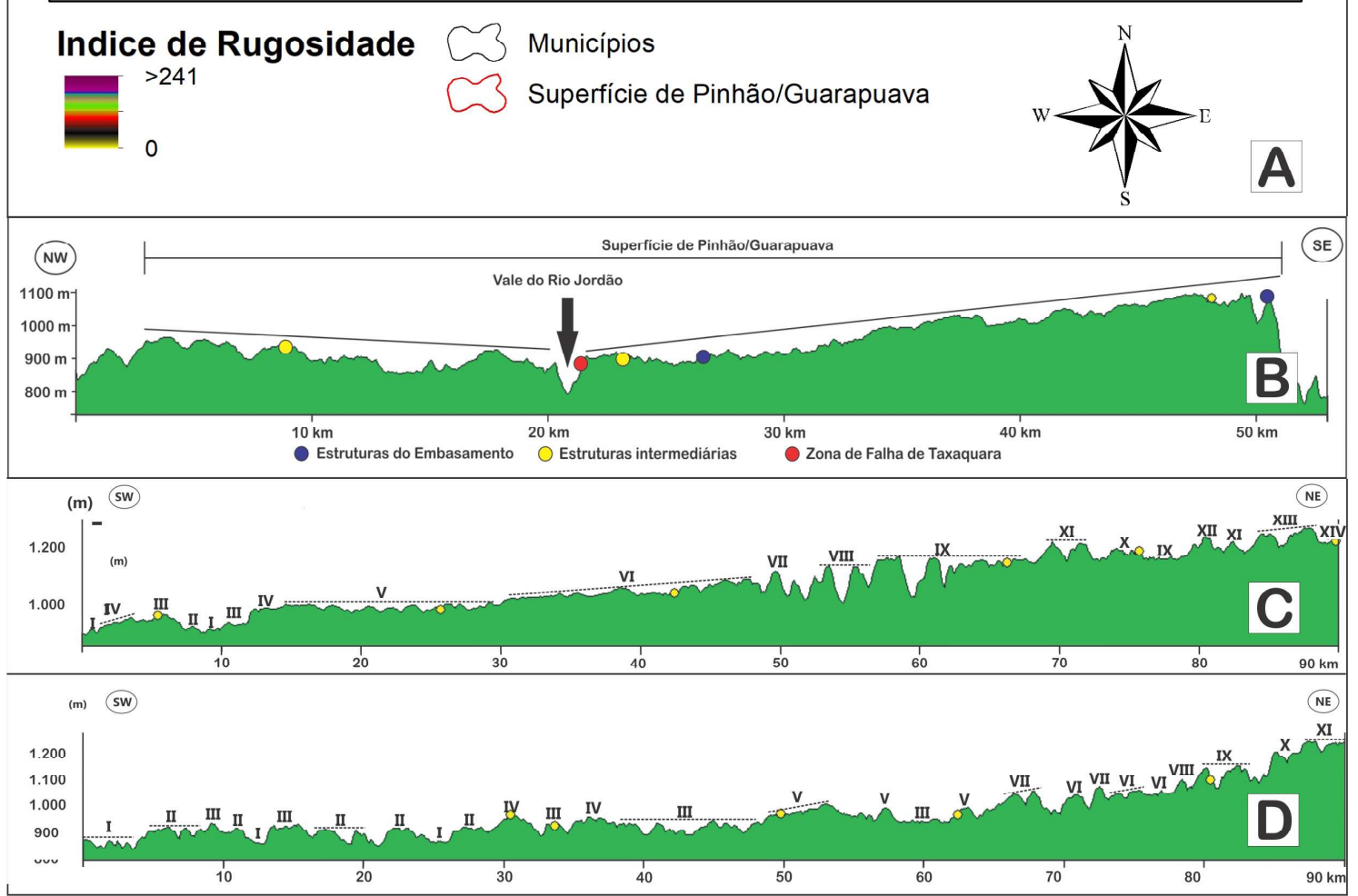

Figura 7 - Individualização da Superficie de Pinhão/Guarapuava, por meio do Índice de Rugosidade do Terreno e imagem sombreada (A). Perfil topográfico no sentido NWSE demonstrando assimetria dos níveis topográficos (B). Níveis topográficos identificados nos setores de Pinhão (C) e Guarapuava (D). 
Enquanto detalhamento da topografia interna do setor de Pinhão, a técnica de nivelamento permitiu extrair perfil topográfico $\mathrm{SW}$ para $\mathrm{NE}$, cruzando transversalmente a superfície, a qual aponta quatorze níveis topográficos (Figura 7C), sendo superior ao sugerido por Peyerl (2016) para esse setor. Os níveis I a IV estão escalonados com aspecto de "teclas de piano", enquanto que outros dois são superfícies típicas escalonadas (V e VI) e dois níveis VI e XIII estão suavemente inclinada, enquanto que os demais são escalonados para SW (Figura 7C). Em detrimento da baixa resolução dos mapeamentos geológicos disponíveis na literatura (MINEROPAR, 2006; 2013), o limite de tais níveis topográficos não permite relacionar com falhas/fraturas e limite de fácies de derrames. Somado a isso, os mapeamentos geológicos realizados para a área que engloba a Superfície de Pinhão/Guarapuava apresam divergências, tanto na natureza dos derrames vulcânicos quanto na respectiva espacialização, mas indicam que a superfície é mantida por derrames ácidos e básicos (NARDY et al. 2002; MINEROPAR, 2006; ARIOLI, 2008; TRATZ, 2009; MINEROPAR, 2013). Isso levaria a pensar que a superfície mapeada transpõe os limites dos derrames ácidos, e, portanto, não apresentaria relação exclusiva com litologia, constituindo típica superfície de erosão apresentada pela literatura clássica (MIGON,2004). Por outro lado, as constatações morfotecônicas de Peyerl (2016) mostram que a neotectônica teve papel importante no estabelecimento das peculiaridades topográficas da Superfície de Pinhão/Guarapuava.

No que se refere ao perfil gerado para o setor de Guarapuava, também extraído de SW para NE, ele revela onze níveis topográficos (Figura 7D). Os níveis I a $\mathrm{V}$, que se encontram na distância até $65 \mathrm{~km}$ do perfil, aparentam vários relevos residuais decorrentes de dissecação pelo sistema hidrográfico do rio Jordão, de uma superfície entre 1000 e $900 \mathrm{~m}$ de altitude. Situação similar é vista no setor de Pinhão (até cerca de $50 \mathrm{~km}$ de distância), onde se encontra relevos residuais em um contínuo topográfico abaixo de $1000 \mathrm{~m}$ de altitude (níveis I a VI) (Figura 7C). A dissecação dessa possível superfície no setor de Guarapuava coincide com os locais de ocorrência de derrames básicos, enquanto que o setor de Pinhão corresponde aos derrames intermediários a ácidos (MINEROPAR, 2013), embora este último menos dissecado. A superfície entre referidas cotas altimétricas foi previamente identificada por Paisani et al. (2008) como superfície interplanálticas num contexto de remanescente de paleosuperfície aplainada, embora que inclinado para SW. Para os autores a etchplanação, intercalada com ação tectônica, foi fundamental no desenvolvimento das superfícies, aqui agrupadas como Superfície de Pinhão/Guarapuava. De fato, crostas ferruginosas na área demonstram que a denudação geoquímica teve papel importante na elaboração da Superfície de Pinhão/Guarapuava, cuja geocronologia dessas pedofeições mostram efetiva contribuição da etchplanação entre o Plioceno e meados do Pleistoceno (RIFFEL et al. 2016).

\section{Conclusões}

No Planalto das Araucárias, a elaboração de modelos digitais de terreno (IRT, relevo sombreado e hipsométrico) e perfis topográficos, permitiram individualizar três superfícies de cimeira (Vacaria, Palmas/Caçador e Pinhão/Guarapuava) entre 760 a $+1300 \mathrm{~m}$ de altitude, as quais se encontram na borda leste desse planalto. O Índice de Rugosidade do Terreno revelou que tais superfícies apresentam aspecto plano, embora dissecada, e com quatro a quatorze níveis altimétricos internos (embutidos). A espacialização das superfícies, a extração de perfis topográficos e o respectivo cotejamento com mapas geológicos e geomorfológicos permitiram avaliar o controle litoestrutural e a ocorrência de níveis geomórficos individualizados previamente na literatura. Quanto a geologia verificou-se que as superfícies transpõem limites laterais dos derrames básicos, intermediários e ácidos, embora predominem sobre estes últimos. Isso leva a pensar que as superfícies de cimeira estão longe de serem consideradas como superfícies controladas apenas pela litologia, como aventada na literatura de forma generalizada para todo o território nacional. Igualmente, limites laterais das superfícies e níveis altimétricos internos das superfícies coincidem, em partes, com falhas/fraturas, apontando para controle neotectônico. As coberturas superficiais caracterizadas em trabalhos da literatura aqui revisados apontam para ação de etchplanação na evolução das superfícies de cimeira, sobretudo entre o Plioceno a Pleistoceno Médio, com remoção de coberturas preexistentes diante de variações climáticas no Quaternário Tardio. 


\section{Agradecimentos}

Ao CNPq (Proc.300902/2015-8) e a CAPES (Coordenação de Aperfeiçoamento de Pessoal de Nível Superior) pelas bolsas de Pesquisador e Mestrado.

\section{Referências Bibliográficas}

AB'SÁBER, A. N. Posição das superfícies aplainadas no Planalto Brasileiro. Notícia Geomorfológica, v. 3, n. 5, p. 5254, 1960a.

AB'SÁBER, A. N. Nótula sobre as Superfícies Aplainadas do Rio Grande do Sul. Notícia Geomorfológica, v. 3, n. 5, p. 5456,1960 b.

AB'SÁBER, A. N.; BIGARELLA, J. J. Superfícies Aplainadas do Primeiro Planalto do Paraná. Boletim Paranaense de Geografia, n. 4-5, p. 116-125, 1961.

AB'SABER, A. N. Compartimentação topográfica e domínios de sedimentação Pós-Cretácios do Brasil. Depto. Geografia, Universidade Federal do Paraná, Curitiba, Tese (concurso para a cadeira de Geografia Física), 80 p. 1962.

AB'SABER, A. N. Da participação das depressões periféricas e superfícies aplainadas na compartimentação do planalto brasileiro. Tese de livre-docência apresentada à Cadeira de Geografia Física da Faculdade de Filosofia, Ciências e Letras da Universidade de São Paulo. São Paulo, 1965

AB'SABER, A. N. Participação das superfícies aplainadas nas paisagens do Rio Grande do Sul. Geomorfologia, São Paulo, n. 11, p. 1-17, 1969.

ADAMS, G. Planation Surfaces: Peneplains, Pediplains, and Etchplains. Dowden, Hutchinson \& Ross, 1975, 476 p.

ANDRADE, G. O. A superfície de aplainamento pliocênica do Nordeste do Brasil. Universidade do Recife, Diretoria Acad. Da Faculdade de Filosofi a, 1958, 44 p.

ANDRADE, G. O.; BIGARELlA, J. J.; LiNS, R. C. Contribuição à geomorfologia e paleoclimatologia do Rio Grande do Sul e do Uruguai. Boletim Paranaense de Geografia. n. 8-9, p. 123-131, 1963.

ANDRADE, G. O.; LINS, R.C. Introdução a morfoclimatologia do nordeste do Brasil. Arquivos do Instituto de Ciências da Terra. V. 3-4, p.11-28, 1965.

ARIOLI, E. E. Arquitetura faciológica da seqüência vulcânica e o significado exploratório das anomalias geoquímicas de elementos do grupo da platina (egp) e metais associados no Sistema Magmático Serra Geral, estado do Paraná, Brasil.
Tese (Doutorado em Geologia exploratória), Programa de Pós-Graduação em Geologia, Universidade Federal do Paraná, Curitiba, 2008, 262p.

BARBOSA, O. Quadro provisório das superfícies de erosão e aplainamentos o Brasil. Notícia Geomorfológica, n. 4, p. 31- 33, 1959.

BHERING, S.B.; SANTOS, H.G. Mapa de Solos do Estado do Paraná. Embrapa Florestas, Embrapa Solos Instituto Agronômico do Paraná, 21, Rio de Janeiro, Brazil p. 15-32, 2008.

BIGAREllA, J. J.; MOUSINHO, M. R.; SILVA, J. X. Pedimentos, pediplanos e depósitos correlativos no Brasil. Boletim Paranaense de Geografia, v. 16/17, p. 117-151, 1965.

CÔRREA, A. C. B.; MENDES, I. A. O problema das superfícies de erosão: novas abordagens conceituais e metodológicas. Revista de Geografia (Recife), v. 18, n.2, p. 70-86, 2002.

DAVIS, W. M. The Geographical Cycle. Geographical Journal, V. 14, N. 5, p. 481-504, 1899.

DE REU, J.; BOURGEOIS, J.; DE SMEDT, P.; ZWERTVAEGHER, A.; ANTROP, M.; BATS, M.; CROMBÉ, P. Measuring the relative topographic position of archaeological sites in the landscape, a case study on the Bronze Age barrows in northwest Belgium. Journal of Archaeological Science, v. 38, n. 12, Pag. 3435-3446, 2011.

DE REU, J.; BOURGEOIS, J.; BATS, M.; ZWERTVAEGHER, A.; GELORINI, V., DE SMEDT, P.; CROMBÉ, P. Application of the topographic position index to heterogeneous landscapes. Geomorphology, v. 186, Pag. 39-49, 2013.

DE MARTONNE, E. Problemas morfológicos do Brasil Tropical Atlântico. Revista Brasileira de Geografia, v. 5, n. 4, p. 532$550,1943$.

FREITAS, R. O. Relevos policíclicos na tectônica do escudo brasileiro. Boletim Paulista de Geografia, n. 7, p. 1-19. 1951.

FREITAS, M.A.; CAYE, B.R.; MACHADO, J.L.F. Diagnóstico dos recursos hídricos subterrâneos do Oeste do Estado de Santa Catarina. Projeto Oeste de Santa Catarina (PROESC). Porto Alegre: CPRM, 2002.

FREITAS, R.C.; ROSTIROLLA, S.P.; FERREIRA, F.J.F. Geoprocessamento multitemático e análise estrutural no Sistema Petrolífero Irati - Rio Bonito, Bacia do Paraná. Boletim de Geociências da Petrobrás, v. 14, n. 1, p. 71-93, 2006.

FODOR, R.V.; MCKEE, E.H.; ROISENBERG, A.; Age distribution of Serra Geral (Paraná) flood basalts, southern 
Brazil. Journal of South American Earth Sciences, n. 2, p. 343-349, 1989.

FLORENZANO, T. G. Geomorfologia: conceitos e tecnologias atuais. São Paulo: Oficina de textos, 2008.

IBGE. Instituto Brasileiro de Geografia e Estatística. Levantamento de Recursos Naturais, Folha SG.22 Curitiba e parte das folhas SG.23 Iguapé e SG.21 Assunción: geologia, geomorfologia, pedologia e vegetação. Projeto RadamBrasil, IBGE, Rio de Janeiro, 1983

JENNESS, J. Topographic Position Index (tpi_jen.avx). Extension for ArcView 3.x, v. 1.3a. Jenness Enterprises. 2006. http://www. jennessent.com/arcview/tpi.htm.

JUSTUS, J.O.; MACHADO, M.L.A.; FRANCO, M.S.M. Geomorfologia. In: SEPLAN/FIBGE. Folha SH.22 Porto Alegre e parte das Folhas SH.21 Uruguaiana e SI.22 Lagoa Mirim: geologia, geomorfologia, pedologia, vegetação, uso potencial da terra. Levantamento de recursos naturais, IBGE, volume 33, p.313-404, 1986.

KING, L. C. Canons of landscape evolution. Bulletin of the Geology Society of America, v. 64, n. 7, p. 721-732, 1953.

KING, L. C. Geomorfologia do Brasil Oriental. Revista Brasileira de Geografia, n. 18, v. 2, p. 147-265, 1956.

LICHT, O. A. B. A revised chemo-chrono-stratigraphic 4-D model for the extrusive rocks of the Paraná Igneous Province. Journal of Volcanology and Geothermal Research. V. 335, pg. 32-52, 2018.

MABESOONE, J. M. Relief of northeastern Brazil and its correlated sediments. Zeitschrift für geomorphologie, Annals of Geomorphology, p. 419-453, 1966.

MARQUES NETO, R.; PEREZ FILHO, A.; Análise morfoestrutural e morfotectônica da bacia do rio Capivari, sul de Minas Gerais: a neotectônica e as superfícies geomorfológicas. Revista Brasileira de Geomorfologia, v. 14, nº 4, pg. 271-277, 2013.

MIGON, P. Planation surface. IN: Goudie, A. S. (org.). Encyclopedia of geomorphology. 2 vols. Routledge, Londres, 2004, $1156 \mathrm{p}$

MINEROPAR S. A. Mapa Geológico do Estado do Paraná, Escala 1:650.000. Curitiba: Mineropar, 2006.

MINEROPAR S. A. 2013. O Grupo Serra Geral no Estado do Paraná. Curitiba: Mineropar, 2013. 2 v.

MOREIRA, M. R. Avaliação dos aspectos texturais na imagem Landsat como subsídio a compartimentação fisiográfica dos municípios de Peruíbe e Itanhaém. Dissertação (Mestrado em Geociências e Meio Ambiente). Instituto de Geociências e Ciências Exatas, Universidade Estadual Paulista, Rio Claro. 2003. 129 p.

NARDY, A.J.R.; OLIVEIRA, M.A.F.; BETANCOURT, R.H.S.; VERDUGO, D.R.H.; MACHADO, F. B. Geologia e estratigrafia da Formação Serra Geral. Geociências, v.21, n.1;2, p.15-32, 2002.

NARDY, A. J. R.; ROSA, M. C.; LUCHETTI, A. C. F.; FERREIRA, M. L. de C.; MACHADO, F. B; OLIVEIRA, M. A. F. Parâmetros Físicos Pré-eruptivos do Magnetismo Ácido da Província Magmática do Paraná: Resultados Preliminares. Geociências, v. 30, n.4 p. 575-588, 2011.

NIMER, E. Clima. IBGE - Instituto Brasileiro de Geografia e Estatística (Ed.), Geografia do Brasil/Região Sul, IBGE, Brasil, pp. 151-187, 1990.

SANTOS, J. M. D. Análise morfotectônica e estrutural da região centro-leste de Santa Catarina (SC). Dissertação (Mestrado em Geologia) - Universidade Federal do Paraná, Curitiba, 2017. 99p.

OLIVEIRA, M.T.G. Evolução mineralógica da alteração laterítica em rochas vulcânicas básicas na borda sudeste da Bacia do Paraná (Rio Grande do Sul e Santa Catarina). Tese (doutorado em Geociências). Instituto de Geociências, Universidade federal do Rio Grande do Sul, 1995. 258p.

PAISANI, J. C.; PONTELLI, M.E.; ANDRES, J. Superfícies aplainadas em zona morfoclimática subtropical úmida no Planalto Basáltico da Bacia do Paraná (SW Paraná / NW Santa Catarina): primeira aproximação. Geociências, v. 27, n. 4, p. 541-553, 2008.

PAisANI. J. C.; PONTELli, M. E.; CALEGARI, M. R. Evolução de bacias de baixa ordem nos 41.000 anos AP Brasil meridional. Mercator, v. 11, p. 131-148, 2012.

GUERRA, S., PAISANI, J.C. Abrangência espacial e temporal da morfogênese e pedogênese no Planalto de Palmas (PR) e Água Doce (SC): subsídio ao estudo da evolução da paisagem quaternária. Geociências, v. 32, p.501-515, 2013.

PAISANI, J.C.; PONTElli, M.E.; CORRÊA, A.C.B.; RODRIGUES, R.A.R. Pedogeochemistry and micromorphology of oxisols - a basis for understanding etchplanation in the Araucárias Plateau (Southern Brazil) in the Late Quaternary. Journal of South American Earth Sciences n 48, p.1-12, 2013. PAISANI, J.C.; PONTELLI, M.E.; OSTERRIETH, M.L.; PAISANI, S.D.L.; FACHIN, A.; GUERRA, S.; OLIVEIRA, L. 
Paleosols in low-order streams and valley heads in the Araucaria Plateau - record of continental environmental conditions in Southern Brazil at the end of MIS 3. Journal of South American Earth Sciences 54, p.57-70, 2014.

PAISANI, J. C.; FACHIN, A.; PONTELLI, M. E.; OSTERRIETH, M. L.; PAISANI, S. D. L.; FUJITA, R. H. Evolução de paleocabeceira de drenagem do Rio Chopinzinho (Sul do Brasil) durante o Quaternário Superior. Revista Brasileira de Geomorfologia, v.17, n.1, p.43-59, 2016.

PEATE, D. W.; MANTOVANI, M. S. N.; HAWKESWORTH, C. J. Geochemical stratigraphy of the Paraná continental flood basalts: borehole evidence. Revista Brasileira de Geociências V.18, no 2, pg. 212-221, 1988

PEATE, D. W. Stratigraphy and Petrogenesiso of the Parana Continental Flood Basalts, Southern Brazil. Ph.D. Thesis, The Open University, Milton Keynes, 359 p, 1989.

PEATE, D. W.; HAWKESWORTH, C. J.; MANTOVANI, M.S.N. Chemical stratigraphy of the Paraná Lavas, South America: classification of magma types and their spatial distribution. Bulletin of Volcanology, v. 55, p. 119-139, 1992.

PEREIRA, J. S.; PAISANI, J. C.; FUJITA, R.H.; PONTELLI, Marga Eliz. HENDGES, E. R.; CAVAZINI, A. J. Caracterização preliminar das formações superficiais das superfícies de São José dos Ausentes (RS) / São Joaquim (SC). In: XI SINAGEO, 2016, maringá. Anais XI SINAGEO, 2016.

PEREIRA, J. S. Pedogênese e morfogênese na superfície de São José dos Ausentes (RS) no quartenário tardio: evidências em paleofundo de vale na bacia hidrográfica do rio dos Touros. Dissertação (Mestrado em Geografia) - Universidade Estadual do Oeste do Paraná, Francisco Beltrão, 2017. 135p.

PEYERL, W. R. L. Morfotectônica da bacia hidrográfica do rio Jordão, região de Guarapuava (PR). Dissertação (Mestrado em Geologia), Universidade Federal do Paraná, Curitiba, 2016. 78p.

RABASSA, J.; CARIGNANO, C.; CIOCCALE, M. Gondwana paleosurfaces in Argentina: an introduction. Geociências, v. 29, n. 4, p. 439-466, 2010.

RABASSA, J.; OLLIER, C. Gondwana Landscapes in southern South America. Argentina, Uruguay and southern Brazil. Dordrecht: Springer Science, 2014.

RIFFEL, S. B.; VASCONCELOS, P. M.; CARMO, I. O.; FARLEY, K. A. Goethite (U-Th)/He geochronology and precipitation mechanisms during weathering of basalts. Chemical Geology, v. 446, p. 18-32, 2016.
RILEY, S.J.; DE GLORIA, S.D.; ELLIOT, R. A Terrain Ruggedness that Quantifies Topographic Heterogeneity. Intermountain Journal of Science, V. 5, N. 1-4, p. 23-27, 1999.

ROSS, J. O relevo brasileiro, as superfícies de aplainamento e os níveis morfológicos. Revista do Departamento de Geografia da USP, v. 5, p. 7-24, 1991.

SAADI, A. Neotectônica da Plataforma Brasileira: esboço e interpretação preliminares. Geonomos, v. 1, n. 1, p. 1-15. 1993.

SAADI, A.; BEZERRA, F.H.R.; COSTA, R.D.; IGREJA, H.L.S. \& FRANZINELLI, E. Neotectônica da Plataforma Brasileira. In: SOUZA C.R.G.; SUGUIO, K.; OLIVEIRA A.M.S. \& OLIVEIRA, P.E., eds. Quaternário do Brasil. Ribeirão Preto, Holos, 2005. p.211-234.

SALGADO, A. A. R. Superfícies de aplainamento: antigos paradigmas revistos pela ótica dos novos conhecimentos geomorfológicos. Revista Geografias, v. 3, n. 1, p. 64-78, 2007.

SAMPAIO, T. V. M.; AUGUSTIN, C. H. R. R. Índice de concentração da rugosidade: uma nova proposta metodológica para o mapeamento e quantificação da dissecação do relevo como subsídio a cartografia geomorfológica. Revista Brasileira de Geomorfologia, v. 15, n. 1, p.47-60, 2014.

SCHENATO, F.; FORMOSO, M.L.L.; MEUNIER, A.; PROUST, D.; MAS, A. Alteration processes of a thick basaltic lava flow of the Paraná Basin (Brazil): petrographic and mineralogical studies. Journal of South American Earth Sciences v. 16, n. 5, p. 423-444, 2003.

SORDI, M. V.; SALGADO, A. A. R.; PAISANI, J.C. compartimentação geomorfológica em áreas de tríplice divisor de águas regional - o caso do planalto de Santa Catarina. Geociências, v. 35, n. 4, p.623-641, 2016.

SILVA, J. M. Análise morfotectônica e estrutural da região centro-leste de Santa Catarina (SC). Dissertação (Mestrado em Geologia), Universidade Federal do Paraná, Curitiba, 2017. 99p.

TRATZ, E. B. As rochas vulcânicas da província magmática do Paraná, suas características de relevo e sua utilização como recurso mineral no município de Guarapuava. Dissertação (mestrado em Geografia). Programa de Pósgraduação em Geografia, Universidade Federal de Santa Catarina, Florianópolis, Santa Catarina, 2009.

TREVISANI, S.; ROCCA, M. MAD: robust image texture analysis for applications in high resolution geomorphometry. Computers and Geosciences, v. 81, p. 78-92. 2015.

VALADÃO, C. R. Evolução de longo termo do relevo do cráton do São Francisco (desnudação, paleossuperfícies e 
movimentos crustais). Tese (Doutorado em Sedimentologia/ Geologia) - Instituto de Geociências, Universidade Federal da Bahia, Salvador, 1998.

VITTE, A. C. A construção da geomorfologia no Brasil. Revista Brasileira de Geomorfologia, v.12, n.3, p.91-108, 2011.

WAYLAND, E. J. Peneplains and some other plataforms. In: ADAMS, G. (org.)Planation surfaces. Dowden, Hutchingon \& Rosss, Inc., p. 355-360, 1975.

WILDNER, W.; RAMGRAB, G. E.; LOPES, L. da C.;
IGLESIAS C. M, DA F. Mapa Geológico do Estado de Santa Catarina. Porto Alegre: CPRM, 2014, Escala: 1:750.000. Programa Geologia do Brasil. Superintendência Regional de Porto Alegre.

ZALÁN, P. V.; WOLFF, S.; CONCEIÇÃO, J. C. de J.; MARQUES, A.; ASTOLFI, M. A. M.; VIEIRA, I. S.; APPI, V. T.; ZANOTTO, O. A. Bacia do Paraná. In: RAJA GABAGLIA, G. P.; MILANI, E. J. (Coords.) Origem e Evolução das Bacias Sedimentares. Ed. Gávea, PETROBRÁS, Rio de Janeiro, p. 135-168, 1990. 